\title{
PENGUJIAN FAKTOR-FAKTOR YANG MEMPENGARUHI PURCHASE INTENTION SECONDATE
}

\author{
Canny Canny ${ }^{1}$, Hetty Karunia Tunjungsari ${ }^{2 *}$ \\ ${ }^{1}$ Jurusan Manajemen Bisnis, Universitas Tarumanagara, Jakarta \\ Email: canny.115170208@stu.untar.ac.id \\ 2 Magister Manajemen, Universitas Tarumanagara, Jakarta \\ Email: hetty@fe.untar.ac.id \\ *penulis korespondensi
}

\begin{abstract}
ABSTRAK
Tujuan dari penelitian ini untuk mengetahui faktor-faktor yang mempengaruhi purchase intention produk kosmetik Korea merek Secondate. Variabel yang diteliti meliputi firm generated content, brand awarenesss, eWOM, brand loyalty, serta purchase intention. Terdapat 200 responden produk Secondate di Jabodetabek yang berpartisipasi dalam survei yang dilakukan secara online. Hasil dari penelitian ini menunjukkan bahwa brand loyalty dan brand awareness dapat memediasi pengaruh firm generated content pada purchase intention, namun eWOM tidak terbukti memiliki peran mediasi dalam pengaruh firm generated content pada purchase intention. Secara teoretis hasil penelitian ini memiliki implikasi dalam pengembangan literatur bidang pemasaran pada era digital. Adapun implikasi praktis hasil penelitian ini dapat dimanfaatkan bagi pemasar dalam menyusun strategi pemasaran digital, khususnya dalam pemasaran di media sosial dengan memanfaatkan firm generated content.
\end{abstract}

Kata Kunci: media sosial, konten, merek, intensi pembelian, pemasaran digital

\begin{abstract}
The purpose of this study was to examine factors affecting purchase intention of Korean cosmetic products under the Secondate brand. Research variables consist of firm generated content, brand awareness, eWOM, brand loyalty, and purchase intention. There are 200 Secondate respondents in Greater Jakarta who participated in the online survey. The results of this study indicate that brand loyalty and brand awareness have mediating effect in the relationship between firm generated content and purchase intention, however, eWOM had no mediating effect in the relationship between firm generated content and purchase intention. Theoretically, the results of this study have implications in the development of marketing literature in the digital era. The practical implications of the study can be used for marketers in developing digital marketing strategies, especially on social media marketing by utilizing firm generated content.
\end{abstract}

Keywords: social media, content, brand, intention, digital marketing.

\section{PENDAhUluan \\ Latar Belakang}

Banyak masyarakat terutama kalangan anak muda yang menyukai fashion Korea karena pakaiannya yang imut, lucu dan sederhana. Skincare Korea juga ramai dibicarakan dan dipercaya memiliki nutrisi yang baik untuk merawat kulit menjadi mulus. Selain itu, make up juga menjadi salah satu pilihan untuk mengubah penampilan pada wajah seseorang dengan bantuan alat kosmetik. Make up korea menjadi salah satu referensi pilihan yang biasa digunakan oleh beberapa masyarakat karena memberikan kesan natural dan cantik. Make up natural sering kali menjadi pusat perhatian, karena banyak wanita yang tidak butuh banyak produk make up namun penampilannya menjadi sangat cantik. Biasanya produk kosmetik yang sering digunakan berupa foundation, concealer, eye shadow, eyeliner, lipstik, dan lain-lain. Dibalik semua itu, ada sebuah permasalahan di dunia kecantikan terutama untuk produk kosmetik bibir seperti lipsitk, lipgloss, liptint dan sebagainya. Sering kali kosmetik yang dipakai dibibir ini sering kali hilang saat makan 
ataupun saat dilap, akhirnya biasanya para wanita akan ke toilet untuk memakai ulang produk kosmetik tersebut agar tidak pucat.

Media sosial merupakan salah satu platform yang biasa digunakan oleh orang-orang untuk mempromosikan usahanya. Media sosial juga dapat menjadi sebuah wadah bagi konsumen untuk menulis, mengedit, dan membagikan informasi apapun yang ingin mereka sampaikan, sekaligus dapat meningkatkan keaktifan interaksi antara konsumen dan perusahaan. Menurut Bruhn et al. (2012), Hinz et al. (2011), dan Mangold dan Faulds (2009), platform media sosial seperti Instagram dan Facebook menjadi lebih aktif karena para brand dapat menyalurkan informasi mengenai produk mereka, dan para konsumen dapat menginvestigasi produk apa yang ingin mereka beli.

Salah satu cara untuk mempertahankan niat beli konsumen pada era sekarang adalah dengan firm generated content yaitu sebuah konten yang dibuat oleh perusahaan di media sosial berupa iklan, story, post, dan lain-lain. Konten tersebut merupakan salah satu wadah komunikasi perusahaan dan konsumen, semakin sering berinteraksi, konsumen akan lebih mengingat merek tersebut yang secara tidak langsung akan mempengaruhi brand awareness. Brand awareness merupakan kemampuan konsumen dalam mengingat sebuah merek di pikiran mereka yang dikemukakan oleh Keller (1993), "brand awareness can represent the presence of a brand in the minds of consumers." Dengan adanya ingatan merek dan dekatnya hubungan antara perusahaan dan konsumen, Balakharisnan et al. (2014) mengatakan bahwa media sosial perusahaan efektif untuk mempromosikan loyalitas merek dan niat beli konsumen, "company social media platform effective promoting brand loyalty and product purchase intention." Dengan demikian maka brand loyalty dapat menjadi salah satu faktor peningkatan niat beli konsumen nanti.

Brand loyalty adalah loyalitas konsumen terhadap sebuah merek, yang berarti konsumen akan lebih memilih sebuah merek dibandingkan dengan merek lain. Hal ini juga berhubungan dengan eWOM karena biasanya konsumen akan memberikan komentar atau review produk di platform online setelah membeli. Konsumen akan merekomendasikan produk Secondate jika produk tersebut baik, namun jika sebaliknya seperti pada batch pertama Secondate di mana kemasan Secondate sempat memiliki beberapa masalah sehingga lip tint mudah bocor, maka ini akan mempengaruhi penjualan dan niat beli konsumen lain.

Penelitian ini mengacu pada theory of planned behavior oleh Azjen (1991) dimana ia menjelaskan bahwa untuk melihat perilaku manusia dapat melalui pendekatan dari banyak tingkat dari faktor psikologis hingga faktor sosial. Seseorang yang dapat memproses informasi yang ada secara penuh memediasi dampak faktor biologis dan lingkungan terhadap perilaku. Konsep yang mengacu pada catatan perilaku seperti sifat kepribadian dan sikap sosial telah memainkan peran penting dalam usaha memprediksi dan menjelaskan perilaku manusia. Faktor utama dalam theory of planned behavior ini adalah niat setiap individu untuk melakukan perilaku tertentu. Niat diartikan dalam menangkap faktor motivasi yang mempengaruhi perilaku. Ini adalah tanda betapa sulitnya orangorang untuk mencoba dan seberapa banyak usaha yang konsumen rencanakan dalam melakukan perilaku tersebut. Semakin kuat niat untuk terlibat dalam sebuah perilaku maka semakin besar kemungkinan kinerjanya.

\section{Purchase Intention}

Menurut Yan (2011), purchase intention didefinisikan sebagai momen saat konsumen mencapai sebuah kesimpulan bahwa mereka pasti akan membeli sebuah produk yang spesifik. Kim dan Ko (2012:1481) juga mengatakan bahwa purchase intention adalah variabel attitudinal untuk 
mengukur kontribusi pelanggan terhadap merek di masa depan. Selain itu, menurut Wu, Yeh, \& Hsiao (2011, p.32), purchase intention mengacu pada kemungkinan bahwa konsumen akan merencanakan atau bersedia membeli produk atau jasa tertentu di masa depan. Schiffman dan Kanuk (2009) mengatakan bahwa semakin besar niat beli, semakin besar juga keinginan konsumen untuk membeli sebuah produk atau jasa. Wu, Yeh, and Hsiao (2011) in Soewandi (2015:206) menambahkan niat membeli mengacu pada kemungkinan yang akan direncanakan atau konsumen bersedia membeli produk atau jasa tertentu di masa depan.

\section{Firm Generated Content}

Fleksibilitas media sosial memungkinkan merek untuk membuat konten dalam berbagai bentuk dan disebarkan melalui platform yang berbeda, proses inilah yang disebut dengan FGC atau Firm Generated Content. Menurut Daiya and Roy (2016); Kumar et al. (2016); Laroche et al. (2013), FGC dapat dideskripsikan yang terbaik dalam mengomunikasikan sebuah informasi, dan perusahaan dapat menyebarkannya dengan bentuk apapun langusng pada halaman media sosial resminya. Kemudian menurut Akar dan Topçu (2011), FGC juga dapat digunakan untuk mempresentasikan sebuah produk di internet dengan harapan visitabilitas merek tersebut akan meningkat.

Kumar et al. (2016:3) mengatakan bahwa firm created social media communication merujuk pada pesan dan konten yang dipublikasikan oleh perusahaan pada sosial media resminya. Adapun menurut Balasubramanian dan Mahajan (2001) serta Chu dan Kim (2011), firm created content yang dibuat oleh perusahaan merupakan fokus utama mereka, yaitu word of mouth (WOM) dan electronic word of mouth (eWOM). Lebih lanjut, Baker, Donthu, \& Kumar (2016) juga mendefinisikan FGC sebagai komunikasi pemasaran yang dibuat oleh perusahaan sebagai media sosial resmi dan dapat membangun hubungan one-on-one dengan konsumen melalui interaksi pada media ini.

\section{Brand Awareness}

Menurut Aaker (1996) brand awareness dapat dideskripsikan sebagai kekuatan yang hadir di kepala konsumen, dan pada dasarnya, brand wareness mengukur seberapa baik konsumen dapat mengenali produk atau jasa dalam berbagai konteks. Selain itu, menurut Keller (1993) serta Macdonald dan Sharp (2000), brand awareness memiliki peran penting dan menjadi faktor kritis pada niat beli konsumen karena mereka cenderung membeli produk yang lebih dikenal dan familiar bagi mereka. Di samping itu Shimp (2010:37) menyatakan bahwa brand awareness merupakan sebuah masalah apakah nama merek tersebut muncul di benak konsumen saat memikirkan kategori produk tertentu dan kemudahan dalam menyebut namanya. Menurut bukti empiris yang ditunjukan oleh Yoo et al. (2000), kesadaran merek dan asosiasi merek dapat digabungkan menjadi satu dimensi.

\section{Brand Loyalty}

Menurut Oliver (1999), loyalitas merek sebagai komitmen konsumen untuk membeli kembali produk atau jasa pilihan mereka di masa depan dan mereka tidak akan mengganti merek pada situasi yang berbeda. Kemudian menurut Yoo dan Donthu (2001), loyalitas merek merupakan salah satu pilihan konsumen terhadap satu merek daripada merek yang lain dan loyalitas merek juga ditunjukan melalui pilihan konsumen berdasarkan kepuasannya serta menolak merek alternatif. Selain itu, Yoo dan Donthu (2001) juga mengemukakan bahwa loyalitas merek dapat menjadi indikator motivasi untuk loyal terhadap sebuah merek dan mencerminkan konsumen memilih merek sebagai pilihan pertama. 


\section{eWOM}

Menurut Akar and Topçu (2011), word of mouth dapat dideskripsikan sebagai penerus informasi produk ke konsumen lain, dan jika word of mouth terjadi dalam lingkungan elektronik, maka itu disebut dengan eWOM. Kredibilitas eWOM adalah tingkat di mana seseorang menganggap rekomendasi dari orang lain dapat dipercaya, benar atau fakta (Cheng dan Zhou, 2010). Lebih lanjut, Litvin, Goldsmith, dan Pan (2008) menjelaskan bahwa eWOM dapat membuat hubungan dan komunitas virtual dengan pengaruh yang jauh di luar pembaca dan pembuat WOM yang menciptakan realita baru dengan mempengaruhi pembaca selama pencarian informasi online mereka. Selain itu, menurut Hennig-Thu, Gwinner, Walsh, dan Gremler (2004), eWOM merupakan potensi setiap pernyataan positif atau negatif oleh pelanggan saat ini atau terhadulu tentang produk atau perusahaan yang disediakan untuk banyak orang dan lembaga melalui internet.

\section{Kaitan antar Variabel}

Menurut Bruhn et al. (2012) komunikasi merek pada media sosial memiliki dampak positif terhadap kesadaran merek, tetapi media tradisional lebih berpengaruh. Selain itu, Jha and Balaji (2015) turut menyatakan bahwa firm-created social media communication akan mempengaruhi kesadaran, fungsi dan citra merek secara positif. Menurut penelitian oleh Soewandi (2015), komunikasi yang diciptakan oleh perusahaan dan pengguna memiliki hubungan positif terhadap kesadaran merek, loyalitas merek dan persepsi kualitas. Komunikasi yang diciptakan oleh perusahaan dan pengguna memiliki hubungan positif terhadap kesadaran merek, loyalitas merek dan persepsi kualitas.

Erdoğmuş and Cicek (2012) mengatakan bahwa ada hubungan positif serupa yang menunjukan bahwa FGC pada platform media sosial yang berbeda merupakan suatu hal yang penting untuk loyalitas merek karena memiliki dampak yang signifikan pada keterlibatan konsumen. Begitu pula dengan yang dikatakan oleh Bruhn et al. (2013) bahwa kualitas interaksi dalam komunitas merek seperti fan pages di Facebook, memiliki dampak positif pada manfaat fungsional, komunitas pengalaman dan simbolik merek, dan meningkatkan loyalitas merek.

Balakrishnan et al. (2014) menyimpulkan bahwa komunikasi pemasaran online memiliki pengaruh positif terhadap loyalitas merek di kalangan generasi Y. Sotiriadis dan Van Zyl (2013), De Matos dan Rossi (2008) mengatakan bahwa literatur yang ada telah mengungkapkan bahwa semakin loyal konsumen terhadap merek apapun, semakin besar kemungkinan konsumen untuk menulis atau membagian eWOM yang positif. Bruhn et al. (2012) juga mengindikasikan bahwa kualitas komunikasi pada komunitas merek memiliki dampak positif terhadap manfaat fungsional dan simbolik komunitas merek dan hasilnya meningkatkan loyalitas merek.

Kesadaran merek merupakan kunci karakteristik merek yang telah terbukti mempengaruhi eWOM dan diakui sebagai komponen penting dari perilaku konsumen online (Aaker,1996); Liao et al., 2012; Godey et al., 2016). Bruhn et al. (2012) mengindikasi bahwa persepsi komunikasi memberikan pengaruh positif terhadap individu tentang sebuah merek, sehingga ini dapat diasumsikan bahwa $e W O M$ dan persepsi konsumen terhadap kesadaran merek berkaitan satu sama lain. Menurut Diansyah dan Nurmalasari (2017), komentar positif dari konsumen yang telah membeli suatu produk dengan kategori tertentu akan memberikan kesan yang baik dan dapat memberikan pengaruh dalam membangun kekuatan merek, sehingga dapat memudahkan konsumen untuk mengingat dan tidak beralih ke merek lain. 
Berdasarkan penelitian sebelumnya yang diteliti oleh Kozinets et al. (2012), Thorson and Rodgers (2006), jaringan media sosial terhadap eWOM dan sebaliknya memiliki dampak positif terhadap antar variabel. Tsimonis and Dimiatris (2014) mengindikasi bahwa media sosial memungkinkan perusahaan untuk menciptakan eWOM yang positif. Menurut Mortazavi et al. (2014), artibut jaringan sosial seperti komunikasi, hubungan sosial, hiburan, informasi dan kemudahan dalam penggunaan dapat digunakan untuk mempromosikan eWOM. Poturak \& Softic (2019) juga membuktikan banyak orang memiliki niat beli pada produk lokal, dan baik dari firm created atau user generated memiliki dampak yang siginifikan pada $e W O M$, sekaligus memberi efek pada brand equity.

Beberapa peneliti seperti Balakrishnan et al. (2014), Goldsmith dan Horowitz (2006), See-to dan Ho (2014), Xia dan Bechwati (2008) menunjukan bahwa eWOM memiliki efek yang lebih besar pada niat beli daripada aktivitas komunikasi lainnya. Pada penelitian yang dilakukan oleh Tseng, Kuo, and Chen (2013), "e-WOM was found to play a very important role on purchase intentions," yaitu peran $e$-WOM sangat penting pada niat beli. Sedangkan menurut Mishra dan Satish (2016), eWOM memiliki dampak pada semua tahap keputusan pembelian.

Menurut Balakrishnan et al. (2014), mereka telah menemukan bahwa pengguna media sosial memiliki respon positif mengenai fakta bahwa FGC dapat memulai dan meningkatkan niat beli. Jha and Balaji (2015) mengatakan bahwa komunikasi firm created social media memiliki dampak positif yang mempengaruhi terhadap kesadaran merek, fungsi dan citra merek yang mengubah ekuitas merek dan niat beli. Selain itu menurut Sidharta, Syah dan Saptaningsih (2021), perusahaan atau organisasi yang fokus pada pemasaran media sosial akan meningkatkan pengetahuan konsumen terhadap produk dan jasa mereka yang akan memberikan dampak positif terhadap niat beli.

Elemen terpenting bagi perusahaan yaitu untuk meningkatkan kinerja penjualan dan menetapkan harga premium, sementara pada saat yang sama, mempertahankan basis pelanggannnya dan merekrut yang baru disebut dengan kesetiaan merek (Malik et al., 2013). Malik et al. (2013) juga menambahkan bahwa loyalitas pada sebuah merek dapat meningkatkan niat beli konsumen. Baker et al. (2010) menyarankan bahwa ekuitas merek yang terdiri dari loyalitas merek, persepsi kualitas, kesadaran merek dapat menghasilkan permintaan konsumen yang lebih besar dalam konteks industri komunikasi seluler.

Aaker (1991), Dodds et al. (1991), Percy dan Rossiter (1992) mengatakan bahwa merek yang lebih populer mungkin lebih mudah dikenali dan beda dari pesaing lainnya. Merek ini akan memiliki niat beli yang lebih tinggi dibandingkan dengan merek lain dengan memiliki kesadaran yang lebih rendah. Berbagai peneliti seperti Chi et al. (2009), Huang dan Sarigöllü (2014), Macdonald dan Sharp (2000) mendukung hasil ini dengan menyatakan bahwa kesadaran merek itu penting jika menyangkut soal niat beli. Chu et al. (2005) dan Tan \& Piron (2002) berargumen bahwa membangun kesadaran merek di pikiran konsumen secara signifikan dapat mempengaruhi perilaku belanja konsumen.

Poulis dan Ryzomiliotis (2019) dalam penelitiannya membuktikan bahwa firm generated content memiliki pengaruh positif pada brand awareness, brand loyalty, eWOM dan purchase intention. Penelitian tersebut menunjukkan adanya peran positif komunikasi perusahaan melalui Facebook dan Instagram dalam membentuk purchase intention. Lebih lanjut, ditemukan juga bahwa komunikasi perusahaan melalui post di Instagram terbukti memiliki dampak yang lebih besar dalam membentuk eWOM dan purchase intention dibandingkan dengan post di Facebook. 
Berdasarkan penjelasan mengenai variabel dan keterkaitan variabel di atas, maka model penelitian dalam penelitian ini adalah sebagai berikut:

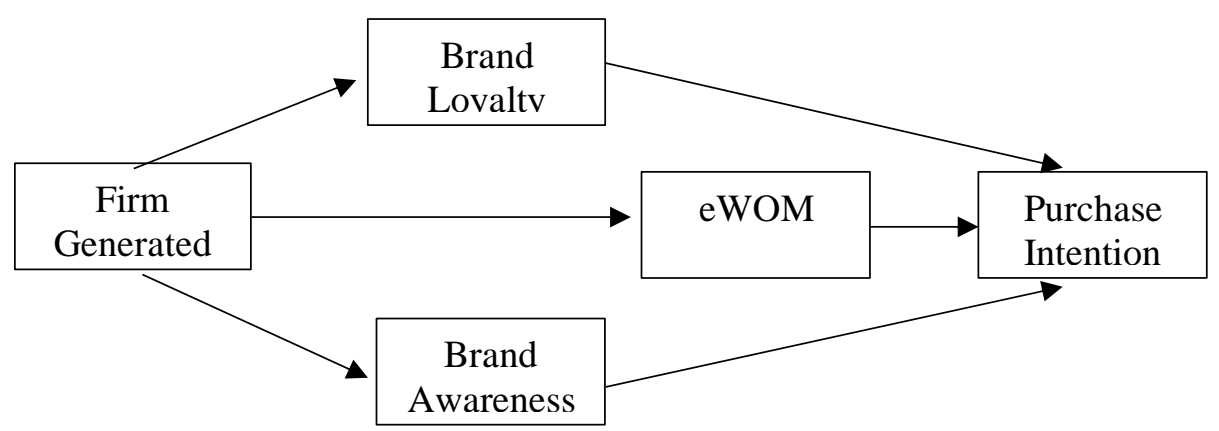

Gambar 1. Model Penelitian

Adapun hipotesis yang diajukan dalam penelitian ini adalah sebagai berikut:

Hipotesis 1: Terdapat mediasi brand loyalty dalam pengaruh firm generated content pada purchase intention

Hipotesis 2 : Terdapat mediasi brand awareness dalam pengaruh firm generated content pada purchase intention

Hipotesis 3: Terdapat mediasi eWOM dalam pengaruh firm generated contet pada purchase intention

\section{METODE PENELITIAN}

Penelitian ini merupakan penelitian kuantitatif dengan desain penelitian deskriptif. Teknik pemilihan sampel yang digunakan pada penelitian ini adalah non-probability sampling dan teknik pengambilan sampel menggunakan teknik convenience sampling. Data diambil menggunakan kuisioner online google form dengan jumlah total sebanyak 213 responden namun hanya 200 data yang dapat digunakan. Pengolahan data penelitian ini menggunakan SmartPLS. Sampel dalam penelitian ini adalah konsumen produk Secondate di Jakarta. Mayoritas responden yang mengisi kuisioner ini adalah wanita yang terdiri dari 184 orang (92\%) dengan rentang usia terbanyak adalah 21-25 tahun yang diisi oleh 128 orang (64\%) dan wilayah domisili terbanyak adalah Jakarta Barat yang diisi oleh 78 orang (39\%). Kemudian mayoritas responden memiliki pekerjaan sebagai mahasiswa/I yang diisi oleh 137 orang $(68,5 \%)$ dengan pendidikan terakhir SMA/SMK/sederajat yang diisi oleh 122 orang (61\%) dan pendapatan per bulan terbanyak yaitu < Rp. 1.000.000 yang diisi oleh 71 orang $(35,5 \%)$.

Tabel 1. Indikator Pengukuran Variabel

\begin{tabular}{ccc}
\hline Variabel & Item & Sumber \\
\hline Firm Generated Content & 4 indikator & Schivinski dan Dabrowski (2016) \\
\hline Brand Loyalty & 11 indikator & Yoo et al. $(2000)$ \\
\hline Brand Awareness & 6 indikator & Yoo et al. (2000) \\
\hline Purchase Intention & 3 indikator & Dodds et al. $(1991)$ \\
\hline$e-W O M$ & 27 indikator & Hennig-Thurau et al. $(2004)$ \\
\hline
\end{tabular}

Penelitian ini menggunakan Skala Likert sebagai alat ukur dan indikator penelitian. Menurut Taherdoost (2019), Skala Likert digunakan untuk mengukur seberapa besar responden setuju terhadap sikap, obyek, orang atau acara. Menurut Budiaji (2013), skala likert yang disarankan adalah 7 poin karena lebih disukai oleh responden dan memiliki kriteria validitas, reliabilitas, 
kekuatan perbedaan dan stabilitas yang cukup baik. Tujuh poin pada Skala Likert di antaranya yaitu angka 1 menyatakan "Sangat Tidak Setuju", angka 2 menyatakan "Tidak Setuju", angka 3 menyatakan "Cukup Tidak Setuju", angka 4 menyatakan "Netral", angka 5 menyatakan "Cukup Setuju", angka 6 menyatakan "Setuju" dan angka 7 menyatakan "Sangat Setuju".

\section{HASIL DAN PEMBAHASAN}

\section{Hasil Analisis Data}

Pada bagian analisis validitas dan reliabilitas, terdapat 51 total indikator untuk mengukur variabel firm generated content, brand awareness, brand loyalty, purchase intention, dan eWOM. Nilai AVE masing-masing variabel memiliki nilai di atas 0,5 (>0,5) yang berarti valid (Hair et al., 2014). Kemudian pada hasil loading factor terdapat 12 indikator yang tidak memenuhi syarat validitas dan memiliki nilai di bawah $0,4(<0,4)$ sehingga dihapus dari model penelitian (Henseler et al., 2009), namun sisanya memiliki nilai di atas $0,5(>0,5)$ yang berarti telah memenuhi syarat validitas konvergen (Ghozali, 2012) serta validitas diskriminan yang menggunakan Heteroit-Monotrait Ration dan Cross Loadings. Terakhir pada analisis reliabilitas, semua nilai variabel dinyatakan reliabel karena nilai Composite Reliability dan Cronbach's Alpha di atas 0,6 (>0,6) (Malhotra, 2020). Hasil pengujian validitas dan reliabilitas dapat dilihat pada Tabel 2 dan 3.

Tabel 2. Hasil Nilai Average Variance Extracted

\begin{tabular}{lc}
\hline \multicolumn{1}{c}{ Variabel } & Average Variance Extracted (AVE) \\
\hline Brand Awareness & 0.687 \\
Brand Loyalty & 0.635 \\
Firm Generated Content & 0.740 \\
Purchase Intention & 0.760 \\
eWOM & 0.552 \\
\hline
\end{tabular}

Tabel 3. Hasil Analisis Reliabilitas

\begin{tabular}{lcc}
\hline \multicolumn{1}{c}{ Variabel } & Cronbach's Alpha & Composite Reliability \\
\hline Brand Awareness & 0,885 & 0,916 \\
Brand Loyalty & 0,935 & 0,945 \\
Firm Generated Content & 0,882 & 0,919 \\
Purchase Intention & 0,840 & 0,904 \\
eWOM & 0,948 & 0,954 \\
\hline
\end{tabular}

Langkah berikutnya adalah melakukan pengujian hipotesis. Pengujian hipotesis dilakukan dengan menggunakan analisis path coefficients, signifikansi p-value, effect size, serta analisis mediasi. Path coefficients memiliki nilai yang berkisar antara -1 sampai +1 , dimana +1 memiliki arti bahwa variabel yang digunakan pada penelitian memiliki hubungan yang positif dan -1 menandakan hubungan variabel yang negatif (Hair et al., 2019). Hipotesis yang signifikan dapat dilihat dari penilaian koefisien parameter dan signifikansi $p$-value pada algoritma bootstrapping. Nilai yang terdapat pada $p$-value harus lebih kecil dari 0.05 (<0.05) (Hair et al., 2019). sementara itu, effect size ditentukan melalui nilai model yang terbagi menjadi tiga kategori yaitu 0.02 yang menandakan efek model yang kecil, 0.15 menandakan efek model yang sedang, dan 0.35 menyatakan efek model yang besar (Hair et.al., 2014). Hipotesis H1 sampai H10 dapat didukung jika path coefficients memiliki nilai yang berkisar antara -1 sampai +1 dan nilai yang terdapat pada $p$-value lebih kecil dari $0.05(<0.05)$.

Terakhir adalah analisis mediasi, efek mediasi yang timbul pada model penelitian dapat dikategorikan sebagai jenis mediasi yang menyeluruh (full mediation), mediasi sebagian (partial mediation) atau tidak dapat memediasi namun hanya terdapat efek langsung yang signifikan (Nitzl et al.,2016). Full mediation atau mediasi yang bersifat mempengaruhi sebagian hubungan variabel. 
Terjadi apabila salah satu hubungan (langsung atau tidak langsung) antar variabel independen dan variabel dependen tidak menunjukkan signifikansi $p$-value lebih kecil dari $0.05(<0.05)$. Adapun partial mediation atau mediasi yang bersifat mempengaruhi seluruh hubungan variabel terjadi apabila hubungan langsung dan tidak langsung antar variabel independen dan variabel dependen menunjukkan signifikansi p-value lebih kecil dari $0.05(<0.05)$.

Tabel 4. Hasil Pengujian Bootstrapping

\begin{tabular}{|c|c|c|c|}
\hline Variabel & Path Coefficients & T-statistics & $P$-values \\
\hline $\begin{array}{l}\text { Firm Generated Content } \rightarrow \text { Brand Loyalty } \rightarrow \\
\text { Purchase Intention }\end{array}$ & 0,360 & 7,978 & 0,000 \\
\hline $\begin{array}{l}\text { Firm Generated Content } \rightarrow \text { Brand Awareness } \rightarrow \\
\text { Purchase Intention }\end{array}$ & 0,110 & 3,284 & 0,001 \\
\hline $\begin{array}{l}\text { Firm Generated Content } \rightarrow \text { eWOM } \rightarrow \text { Purchase } \\
\text { Intention }\end{array}$ & 0,024 & 0,020 & 0,984 \\
\hline
\end{tabular}

Tabel 5. Hasil Pengujian Effect Size $\left(\mathrm{f}^{2}\right)$

\begin{tabular}{lccc}
\hline \multicolumn{1}{c}{ Variabel } & $\begin{array}{c}\text { Brand } \\
\text { Awareness }\end{array}$ & Brand Loyalty & Purchase Intention \\
\hline Brand Awareness & - & - & 0,142 \\
Brand Loyalty & - & - & 0,557 \\
Firm Generated Content & 0,213 & 0,507 & 0,004 \\
eWOM & - & - & 0,000 \\
\hline
\end{tabular}

Berdasarkan hasil pengujian effect size yang ditampilkan pada Tabel 5 di atas, firm generated content memiliki pengaruh sedang pada brand awareness dengan nilai interpretasi 0,213, pengaruh besar pada brand loyalty dengan nilai interpretasi 0,507 dan pengaruh kecil pada purchase intention dan eWOM dengan nilai interpretasi 0,004 dan 0,003. Brand awareness memiliki pengaruh kecil pada purchase intention dengan nilai interpretasi 0,142 . Sementara itu, brand loyalty memiliki pengaruh besar pada purchase intention dengan nilai interpretasi 0,557. Selanjutnya, eWOM memiliki pengaruh kecil pada purchase intention dengan nilai interpretasi 0,000. Maka dari itu dapat disimpulkan bahwa variabel brand loyalty memiliki pengaruh paling besar dan kuat pada purchase intention jika dibandingkan dengan variabel brand awareness, firm generated content, dan $e W O M$.

\section{Diskusi}

Berdasarkan hasil pengujian hipotesis pada Tabel 4 dapat dilihat bahwa Hipotesis 1 dan Hipotesis 2 didukung oleh data secara statistik. Hal ini menunjukan bahwa firm generated content atau komunikasi dan konten-konten yang dibuat oleh perusahaan terbukti berpengaruh positif dengan signifikan yang sedang terhadap purchase intention dengan mediasi brand loyalty dan brand awareness. Hasil ini mendukung penelitian Poulis dan Ryzomiliotis (2019) yang menyatakan bahwa firm generated content, brand loyalty dan brand awareness memiliki pengaruh positif pada purchase intention. Merujuk pada penelitian tersebut, dapat disimpulkan juga bahwa untuk dapat membentuk purchase intention Secondate, perusahaan perlu memperhatikan konten pesan yang di-posting di media sosial agar dapat meningkatkan brand awareness dan brand loyalty konsumen. Berbeda dengan penelitian Poturak \& Softic (2019), hasil pengujian Hipotesis 3, ditemukan bahwa mediasi $e W O M$ dalam pengaruh firm generated content pada purchase intention tidak didukung oleh data secara statistik. Hal ini dapat diartikan bahwa loyalitas serta kesadaran merek lebih dibutuhkan oleh konsumen untuk membeli Secondate dibandingkan dengan eWOM mengenai produk itu sendiri. Kesimpulannya, konsumen akan membeli produk Secondate jika sudah yakin dan mengenali merek Secondate atau pernah membeli dan akan kembali membeli, walaupun Secondate sering membuat konten mengenai produk tanpa mengenalkan mereknya ke publik. Saat 
seseorang yang belum pernah mengenal produk Secondate membaca konten di media sosial mengenai Secondate, kemungkinan besar kurang tertarik untuk membeli karena dianggap asing, walaupun dia mendapatkan pesan $e W O M$ dari konsumen Secondate lainnya.

\section{KESIMPULAN DAN SARAN}

Penelitian ini bertujuan untuk menguji efek mediasi brand loyalty, brand awareness, serta $e$ WOM dalam pengaruh firm generated content pada purchase intention produk kosmetik Korea merek Secondate. Kesimpulan yang dapat diambil pada penelitian ini adalah terdapat peran mediasi brand loyalty dan brand awareness dalam pengaruh firm generated content pada purchase intention, namun $e W O M$ tidak memiliki efek mediasi dalam pengaruh firm generated content pada purchase intention. Dari hasil penelitian ini, peneliti menyarankan agar perusahaan dapat mempertahankan keaktifan di media sosial dalam konten positif semaksimal mungkin agar dapat meningkatkan kesadaran terhadap sebuah merek, karena penyebaran informasi saat ini sangat cepat dan memberikan keuntungan dalam pemasaran merek. Peneliti juga menyarankan perusahaan untuk mempertahankan kualitas produk dan layanan pelanggan yang baik, agar konsumen tetap nyaman dalam berbelanja dan pelanggan dapat mempertahankan loyalitasnya. Variabel $e$ WOM tidak didukung oleh data dalam memediasi pengaruh firm generated content pada purchase intention. Di masa mendatang dapat dilakukan pengujian pada variabel country of origin sebagai variabel mediasi lainnya.

\section{Ucapan Terima Kasih}

Peneliti mengucapkan terima kasih pada LPPM Universitas Tarumanagara yang telah memberikan dana hibah penelitian Tugas Akhir pada periode 1 tahun 2021.

\section{REFERENSI}

Abedi, E., Ghorbanzadeh, D., \& Rahehagh, A. (2019). Influence of eWOM information on consumers' behavioral intentions in mobile social networks: Evidence of Iran. Journal of Advances in Management Research, 17(1), 84-109. (https://doi.org/10.1108/JAMR-042019-0058)

balas.org. (2018). Firm Generated Content in Social Media Marketing and its impact on Brand Image, Purchase Intention and eWOM for Complex Decisión Making Track: Marketing Management KEY WORDS: social media marketing, electronic word of mouth, brand equity. Semantic Scholar.

Female Daily Network. (n.d.). SECONDATE Milky Gel Lip Tint Naughty - Review. Female Daily. (https://reviews.femaledaily.com/products/lips/lip-tint/secondate/milky-gel-lip-tint27 tab=reviews)

Ghozali, I. (2012). Aplikasi Analisis Multivariabel Dengan program IBM SPSS 20. Semarang: BP Universitas Diponegoro.

Hair, J. F., Sarstedt, M., Hopkins, L., \& Kuppelwieser, V. G. (2014). Partial least squares structural equation modeling (PLS-SEM): An emerging tool in 57 business research. In European Business Review (Vol. 26, Issue 2). (https://doi.org/10.1108/EBR-10-2013-0128)

Henseler, J., Ringle, C. M., \& Sinkovics, R. R. (2009). The use of partial least squares path modeling in international marketing. In Advances in International Marketing (Vol. 20). (https://doi.org/10.1108/S1474-7979(2009)0000020014)

Hermaren, V., \& Achyar, A. (2018). The effect of firm created content and user generated content evaluation on customer-based brand equity. INOBIS: Jurnal Inovasi Bisnis Dan Manajemen Indonesia, 2(1), 86-100. (https://doi.org/10.31842/jurnal-inobis.v2i1.63)

Ismail, A. R. (2017). The influence of perceived social media marketing activities on brand loyalty: The mediation effect of brand and value consciousness. Asia Pacific Journal of Marketing 
and Logistics, 29(1), 129-144. (https://doi.org/10.1108/APJML-10-2015-0154)

Kim, J., Melton, R., Min, J. E., \& Kim, B. Y. (2020). Who says what?: exploring the impacts of content type and blog type on brand credibility, brand similarity and eWOM intention. Journal of Fashion Marketing and Management, 24(4), 611-630. (https://doi.org/10.1108/JFMM-03-2019-0041)

Lee, J. E., Goh, M. L., \& Mohd Noor, M. N. Bin. (2019). Understanding purchase intention of university students towards skin care products. PSU Research Review, 3(3), 161-178. (https://doi.org/10.1108/prr-11-2018-0031)

Mahnoor M. (2018). The impact of Social Media Communication on Brand Awareness, Brand Equity and Purchase Intention: A study of Apparel Brands in Pakistan. 3(2), 204-213.

Malhotra. (2020). Marketing Research: Applied Insight.

Poulis, A., Rizomyliotis, I., \& Konstantoulaki, K. (2019). Do firms still need to be social? Firm generated content in social media. Information Technology and People, 32(2), 387-404. (https://doi.org/10.1108/ITP-03-2018-0134)

Sekaran, U. dan Bougie, R. (2016). Research Methods for Business: A Skill-Building Approach (7th ed.). West Sussex: John Wiley \& Sons.

Sidharta, M. W., Syah, T. Y. R., \& Saptaningsih, A. B. (2021). The Relationship Between Social Media Communication and Word of Mouth Inside Brand Image and Purchase Intention. 05(01).

Sijoria, C., Mukherjee, S., \& Datta, B. (2018). Impact of the antecedents of eWOM on CBBE. Marketing Intelligence and Planning, 36(5), 528-542. (https://doi.org/10.1108/MIP-102017-0221)

Susanti, S. A., Sawaki, I. A., Octora, Y., \& Primadi, A. (2020). the Influence of Brand Awareness , Brand Image on E-Wom Mediated By Brand Trust in the Airasia Refund Process During Covid-19 Pandemic in Jakarta 2020. Crostlog 2020, 458-466.

Syamsiyah, M. N. (2020, December 30). 10 Brand Kosmetik Lokal yang Sukses Mencuri Perhatian di 2020. kumparan. (https://kumparan.com/kumparanwoman/10-brand-kosmetik-lokalyang-sukses-mencuri-perhatian-di-2020-1uscUudMJrh.)

Taherdoost, H. (2019). What Is the Best Response Scale for Survey and Questionnaire Design; Review of Different Lengths of Rating Scale / Attitude Scale / Likert Scale. International Journal of Academic Research in Management (IJARM), Vol. 8. pp.-02557308

Wang, W. T., \& Li, H. M. (2012). Factors influencing mobile services adoption: A brand-equity $\begin{array}{llll}\text { perspective. Internet } & \text { Research, } & \text { 142-179), }\end{array}$ (https://doi.org/10.1108/10662241211214548)

Wijaya, K. R., \& Kusumawati, A. (2018). The Power of Instagram Communication Between Firm and Endorsed Celebrities Towards Brand Awareness and Purchase Intention Amongst Millenials (Study of VIVO Smartphone Instagram Communication in Indonesia). Jurnal Administrasi Bisnis, 62(1), 181-189. administrasibisnis.studentjournal.ub.ac.id

Yan, X., Shah, A. M., Zhai, L., Khan, S., \& Shah, S. A. (2018). Impact of Mobile Electronic Word of Mouth (EWOM) on Consumers Purchase Intentions in the Fast-Causal Restaurant Industry in Indonesia. Proceedings of the 51st Hawaii International Conference on System Sciences. (https://doi.org/10.24251/hicss.2018.479) 